\title{
Effects of increasing intake of soybean oil on synthesis of testosterone in Leydig cells
}

\author{
Yu Su ${ }^{1,2}$, Zhenhua Tian 1,3, Xiangyu Qi ${ }^{1,2}$, Dandan Luo ${ }^{1,2}$, Luna Liu ${ }^{1,2}$, Shuang Liu ${ }^{1,2}$, Dongmei Zheng ${ }^{1,3}$,
} Fang Wei ${ }^{4}$, Zhao He $\mathrm{e}^{1,2,3^{*}}$ and Qingbo Guan ${ }^{1,2,3^{*}}$ (])

\begin{abstract}
Background: Soybean oil is a very common edible oil in daily life. With the changes in the dietary composition, the intake of soybean oil increased. However, the effects of dietary intake of soybean oil on testosterone production are still unclear.
\end{abstract}

Methods: In order to study the effects of increasing intake of soybean oil on the synthesis of testosterone in Leydig cells, we fed male C57BL/6 mice on the diet which added 20\% soybean salad oil (SOY group). We detected the hormone levels by enzyme-linked immunosorbent assay (ELISA) kits and serum fatty acid composition by gas chromatography, and analyzed the expression of steroidogenic enzymes by Real-Time PCR or immunoblotting analysis.

Results: After the 16-week feeding period, serum linoleic acid (LA) and a-linolenic acid (ALA) significantly increased and serum palmitic acid (PA) significantly decreased in SOY group mice. Compared to the normal diet (ND group), increasing intake of soybean oil raised the luteinizing hormone (LH) levels and up-regulated luteinizing hormone/ chorionic gonadotropin receptor (LHCGR), steroidogenic acute regulatory protein (StAR) and cytochrome P450 family 11 subfamily A member I (CYP11A1). Testosterone levels in SOY group were higher than that in the ND group, and significantly difference showed.

Conclusions: Increasing intake of soybean oil could raise the serum LA and ALA levels and decrease serum PA levels. This could activate the LH/LHCGR pathway and improve the function of steroid synthesis in Leydig cells, and finally lead to the elevated testosterone levels.

Keywords: Soybean oil, Linoleic acid (LA), a-linolenic acid (ALA), Testosterone, Luteinizing hormone (LH)

\section{Introduction}

Testosterone $(\mathrm{T})$, as an important steroid hormone, plays a key role in the physiological processes of male growth and development, maintenance of fertility, and material metabolism [1-3]. A cross-sectional survey reported that testosterone levels declined $25 \%$ among adolescent and young adult men in the USA in 2015-2016 compared to sixteen years ago [4]. The lack of testosterone leads

\footnotetext{
*Correspondence: zhaohe@sdu.edu.cn; doctorguanqingbo@163.com ${ }^{3}$ Department of Endocrinology and Metabolism, Shandong Provincial Hospital Affiliated to Shandong First Medical University, Jinan 250021, Shandong, China

Full list of author information is available at the end of the article
}

to male sexual dysfunction, accelerates the aging of the body's organs, induces the occurrence of systemic diseases, and thus, seriously affects the quality of life $[5,6]$. Therefore, the decline in testosterone levels is a major concern of the public health. It has significant meanings to explore the underlying mechanism and potential treatment of testosterone level decline.

Polyunsaturated fatty acids (PUFAs) are nutrients required for a variety of physiologic functions that exert important health effects. A nationwide cross-sectional survey of Koreans shows that soybean oil was the major source of PUFAs [7]. Soybean oil is a very common edible oil in daily life. Some studies have revealed that soybean oil improves myocardial function and it has original author(s) and the source, provide a link to the Creative Commons licence, and indicate if changes were made. The images or other third party material in this article are included in the article's Creative Commons licence, unless indicated otherwise in a credit line to the material. If material is not included in the article's Creative Commons licence and your intended use is not permitted by statutory regulation or exceeds the permitted use, you will need to obtain permission directly from the copyright holder. To view a copy of this licence, visit http://creativecommons.org/licenses/by/4.0/. The Creative Commons Public Domain Dedication waiver (http://creativeco mmons.org/publicdomain/zero/1.0/) applies to the data made available in this article, unless otherwise stated in a credit line to the data. 
anti-oxidation effect $[8,9]$. The main component of soybean oil is linoleic acid (C18:2 $\omega-6$, LA), it is a kind of $\omega-6$ PUFAs [10]. In addition, compared with other edible oils, soybean oil is rich in $\alpha$-linolenic acid (C18:3 $\omega$-3, ALA) [11]. LA and ALA are essential because they cannot be synthesized by humans and must be obtained through diet, primarily from plant oils [12]. In the United States, there has been a rapidly 1000-fold increase in the consumption of soybean oil during the twentieth century [13]. But the effect of increasing intake of soybean oil on testosterone synthesis and its underlying mechanisms remains unknown.

Male testosterone is mainly produced by testicular Leydig cells, and is regulated by the hypothalamic-pituitary axis. After luteinizing hormone (LH) acting on the luteinizing hormone/chorionic gonadotropin receptor (LHCGR) on Leydig cells, cholesterol is transported into the mitochondria via the Steroidogenic acute regulatory protein (StAR) [14], which is considered as the rate-limiting step in testosterone synthesis [15], and finally converted to testosterone by steroidogenic enzymes such as cytochrome P450 family 11 subfamily A member 1

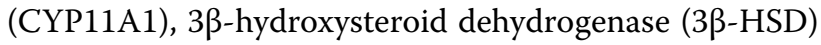
and cytochrome P450 family 17 subfamily A member 1 (CYP17A1) [16, 17]. Increasing intake soybean oil may affect testosterone production through one or more points in the process mentioned above.

In our study, we established an animal model by adding soybean oil to the diet to compare the effects of increasing intake of soybean oil on testosterone synthesis. This study suggests that increasing intake of soybean oil could activate the LH/LHCGR pathway and promote testosterone production.

\section{Methods}

\section{Animals and treatment}

All animal experiments were approved by the Animal Ethics Committee of Shandong Provincial Hospital and performed according to the Shandong Provincial Hospital Animal Care and Use Committee. Fourteen male C57BL/6 mice at 6-7 weeks of age were constructed from Beijing Vital River Laboratory Animal Technology Co., Ltd. (Beijing, China). They were housed in a constant temperature-controlled room for a 12-h light/dark cycle. After acclimated for one week, they were divided into two groups and assigned to one of the following three diets for 16 weeks: (1) normal diet (ND group), (2) soybean oil diet (SOY group). All the diets were provided by Beijing Keaoxieli Co., Ltd (Beijing, China). The normal diet provided calories of $3.40 \mathrm{kcal} / \mathrm{g}$ (protein $23.07 \%$, fat $11.85 \%$, carbohydrate $65.08 \%$ ). Additional file 1: Table S1 shows the ingredients of normal diet. The soybean oil diet was prepared by supplementing normal diet with about $20 \%$ soybean salad oil (by weight), it was providing calories of $5.36 \mathrm{kcal} / \mathrm{g}$ (protein $14.62 \%$, fat $44.13 \%$, carbohydrate $41.25 \%$ ). The fatty acid compositions of soybean oil and the diets are shown in Additional file 2: Table S2 and Additional file 3: Table S3. To measure food intake, we separated animals in single cages for 7 days. A weighed amount of food was given and the weight consumed (evaluated as the difference between the original amount and the food left in the cage) was measured perday. The mice were killed for the subsequent experiments after 16 weeks.

\section{Measurement of lipid profile and sex hormone}

At the 16th week, after being fasted for $8 \mathrm{~h}$, the mice were anaesthetized with pentobarbital sodium and the blood samples were collected from eyes. The blood was centrifuged to separate the mice serum. Triglyceride (TG), total cholesterol (TC), low-density lipoprotein cholesterol (LDL-C), high-density lipoprotein cholesterol (HDL-C) and glucose (Glu) was measured with biochemical analyzer (Mindray Bio Medical Electronics Co., Ltd.). Serum testosterone (CUSABIO Biotech Co., Ltd., Wuhan, China) and serum luteinizing hormone (CloudClone Corp, Houston, USA) levels were measured by an enzyme-linked immunosorbent assay (ELISA) kit according to the manufacturer's protocols.

\section{Gas chromatographic analysis of fatty acids}

Added 1\% sulfuric acid methanol solution to the serum and esterified the samples at $80{ }^{\circ} \mathrm{C}$. Then the samples were extracted with $n$-hexane and washed with ddH2O. Added anhydrous sodium sulfate powder to the supernatant to remove excess water. The samples were centrifuged to separate the supernatant. Methyl salicylate as an internal standard was added to the supernatant. Samples were measured by Agilent 6890N/5975B gas-mass spectrometer (Agilent, USA).

\section{RNA isolation and Real-time PCR}

RNAiso Reagent (Takara, Tokyo, Japan) was used to extract total RNA from testicular tissues. RNA samples were reverse-transcribed by reverse transcription kit (PrimeScript ${ }^{\circledR}$ RT Reagent Kit (Perfect Real Time), TaKaRa, Japan) according to the manufacturer's instructions. The cDNA obtained by reverse transcription was used as a template for RT-PCR conducted with the LightCycler480 (Roche). Use the $2^{-\Delta \Delta C t}$ method to calculate the relative expression of mRNA. The sequences of the PCR primers (synthesized by Qingdaoqingke Biotech Co., Ltd., China) of LHCGR (5'- GATGCACAGTGGCACCTTC and 5'TCAGCGTGGCAACCAGTAG), STAR (5'-GGAGCA GAGTGGTGTCATCAGA and $5^{\prime}$-AGGTGGTTGGCG AACTCTATCT), SF-1 (5'-CCCAAGAGTTAGTGCTCC 
AGT and 5'-CTGGGCGTCCTTTACGAGG), CYP11A1 (5'-TGCTTGAGAGGCTGGAAGTTGA and 5'-CGG ATTGCGGAGCTGGAGAT), CYP17A1 (5'-GTACCC AGGCGAAGAGAATAGA and $5^{\prime}$-GCCCAAGTCAAA GACACCTAAT), 3ß-HSD (5'-AGCTCTGGACAAAGT ATTCCGA and $5^{\prime}$-GCCTCCAATAGGTTCTGGGT) and $\beta$-actin (5'-GGCTGTATTCCCCTCCATCG and 5'-CCA GTTGGTAACAATGCCATGT).

\section{Immunoblotting analysis}

Total protein was extracted from testicular tissues with protein lysis buffer (RIPA: PMSF =99:1), and determined the concentration by the BCA assay. After denaturation, protein samples were subjected to SDS-PAGE, electrophoretically transferred to membranes. The membrane was blocked in 5\% skimmed milk in TBST buffer for $1 \mathrm{~h}$, and then incubated with primary antibody overnight at $4{ }^{\circ} \mathrm{C}$. StAR $(1: 1000)$ and CYP11A1 (1:1000) is from Cell Signaling Technology, 3 $\beta$-HSD (1:500) is from Santa Cruz; LHCGR (1:500), CYP17A1 (1:1000) and GAPDH (1:5000) are from Proteintech. The membrane was incubated with the appropriate secondary antibodies for $1 \mathrm{~h}$. Finally, we visualized and quantified the bands.

\section{Immunohistochemistry}

The testes were fixed for $24 \mathrm{~h}$ and then embedded in paraffin. For the immunohistochemistry assay, all steps followed standard techniques. The paraffin sections were deparaffinized, hydrated, and antigen repaired. Then incubated them overnight at $4{ }^{\circ} \mathrm{C}$ with the primary rabbit anti-LHCGR primary antibody (Proteintech,1:200), and use BSA as a negative control. The next day, they were incubated with the secondary antibody at $37^{\circ} \mathrm{C}$, and then developed with DAB kit (ZSGB-BIO, Beijing, China) and counterstained with hematoxylin.

\section{Statistical analysis}

All data were analyzed by GraphPad Prism (v.8, GraphPad Software Inc, CA). The intergroup comparison was determined by t-test. All data are expressed as mean $\pm \mathrm{SD}$, and it is statistically significant when $P<0.05$.

\section{Results}

Effect of increasing intake of soybean oil on serum lipid profiles and glucose levels in the mice

We measured the weight of the mice after the 16th weeks' feeding. Comparing with the ND group, the body weight of the mice in the SOY group increased slightly, but it did not have statistical difference (Fig. 1A). There was no significant difference in food intake between the two groups (Fig. 1B). After the 16-week feeding period, no significant difference was seen in testicular weight among the two groups (Fig. 1C). To observe the effects of adding soybean oil on circulating blood lipids and glucose (Glu), we tested the serum levels of LDL-C, HDLC, TC, TG and Glu. As shown in the Fig. 1D, increasing intake of soybean oil did not affect the blood lipid profiles and Glu levels; there was no significant difference among the two groups.

\section{Increasing intake of soybean oil influenced the serum hormone levels in the mice}

In order to explore the effects of increasing intake of soybean oil on serum sex hormones, serum testosterone and LH levels were detected. The testosterone levels of the mice in SOY group were observed dramatically increasing compared with those of the ND group (Fig. 2A; $P<0.01)$. LH acts on Leydig cells and promotes the production of testosterone. The serum LH levels of mice in the SOY groups significantly increased compared with the ND group. (Fig. 2B). Increasing intake of soybean oil could increase the LH levels, and the high LH levels may further promote the production of testosterone.

\section{Increasing intake of soybean oil influenced the serum fatty acid composition in the mice}

Increasing intake of soybean oil affected LH levels and testosterone production. In order to observe the effect of soybean oil on the serum fatty acid composition, we analyzed the serum by gas chromatography. Soybean oil is the source of LA and ALA. As shown in Table 1, compared with ND group, the serum LA and ALA levels in the mice of the SOY group were significantly increased. And the serum palmitic acid (C16:0, PA) and total saturated fatty acid were significantly decreased. Comparing with the ND group, with the percent of LA and ALA increased, the percent of C14:0, C14:1, C22:1, C24:1, C18:3, C20:4, C20:3, C20:5 and C22:6 declined in the SOY group. It is suggested that increasing intake of soybean oil may influence serum hormone levels by the changes of serum fatty acid composition.

\section{Increasing intake of soybean oil enhanced steroidogenic enzyme expression in the testis}

Testosterone synthesis is a complex process in which the key enzymes StAR, CYP11A1, CYP17A1, and $3 \beta-H S D$ are involved. In order to explore the effect of increasing intake of soybean oil on the enzymes related to the testosterone synthesis pathway of Leydig cells, we used RT-PCR and immunoblotting analysis to detect the expression of these proteins. Compared with the ND group, the mRNA levels of StAR, CYP11A1, and CYP17A1 in the SOY group all significantly increased (Fig. 3A). There was no difference between the two groups of $3 \beta-H S D$ mRNA levels. We also tested the mRNA levels of steroidogenic factor 1 (SF-1), which 

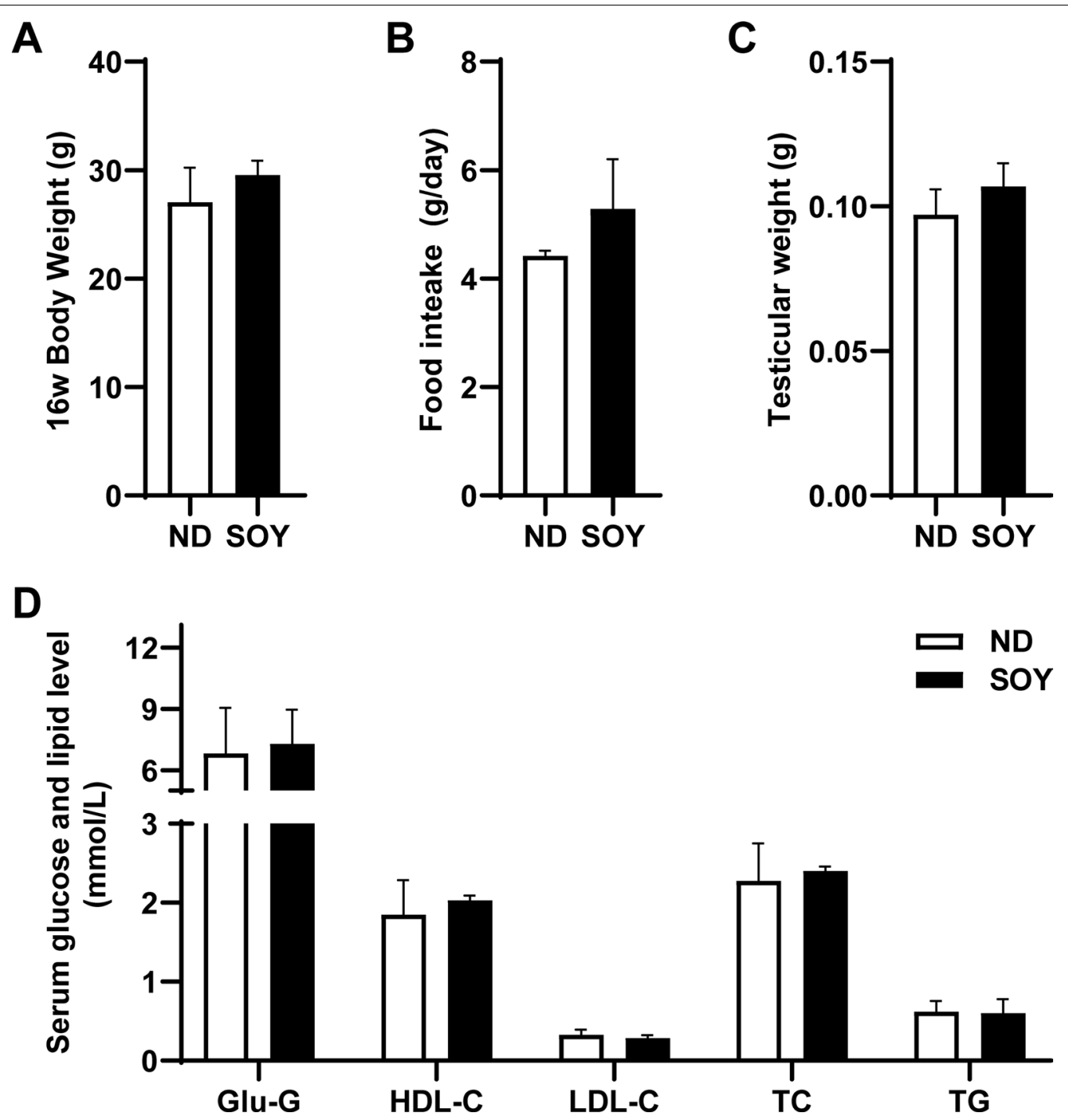

Fig. 1 Effect of increasing intake of soybean oil on serum lipid profiles and glucose levels in the mice. A The body weight at the 16th week of mice fed with ND or SOY group ( $n=7$ for each group). B The amount of food intake of the ND or SOY group ( $n=3$ for each group). C The weight of testis in the ND or SOY group ( $n=7$ for each group). D Comparison of serum lipid levels and Glu levels in the ND or SOY group ( $n=6$ for each group). Data are expressed as mean \pm SD

could promote the transcription of testosterone synthesis related genes such as StAR, CYP11A1 and 3 $\beta$-HSD [18, 19]. We found that the mRNA levels of SF-1 in the SOY group significantly increased compared to ND group. As shown in Fig. 3C, consistent with the mRNA levels, the protein expression of StAR and CYP11A1 increased in the SOY group in comparison to ND group. In Fig. 3, no significant difference about CYP17A1 at the protein levels (Fig. 3C), although the mRNA levels of CYP17A1 in the SOY group significantly increased compared to ND group. And there was no significant difference in protein levels about $3 \beta$-HSD among the two groups. In summary, increasing intake of soybean oil promoted the expression of SF-1 to enhance the transcription of StAR and CYP11A1, promoted the expression of them further, and then increased the synthesis of testosterone.

\section{Increasing intake of soybean oil up-regulated}

the expression of LHCGR in the mice

We observed that the serum LH levels in the SOY group increased. Increasing intake of SOY may promote testosterone synthesis by high LH levels. LH need to combine with the LHCGR on the Leydig cell to promote testosterone production. Therefore, we used RT-PCR, immunoblotting analysis and immunohistochemistry to observe the effects of soybean oil on LHCGR. As Fig. 4A shown, 

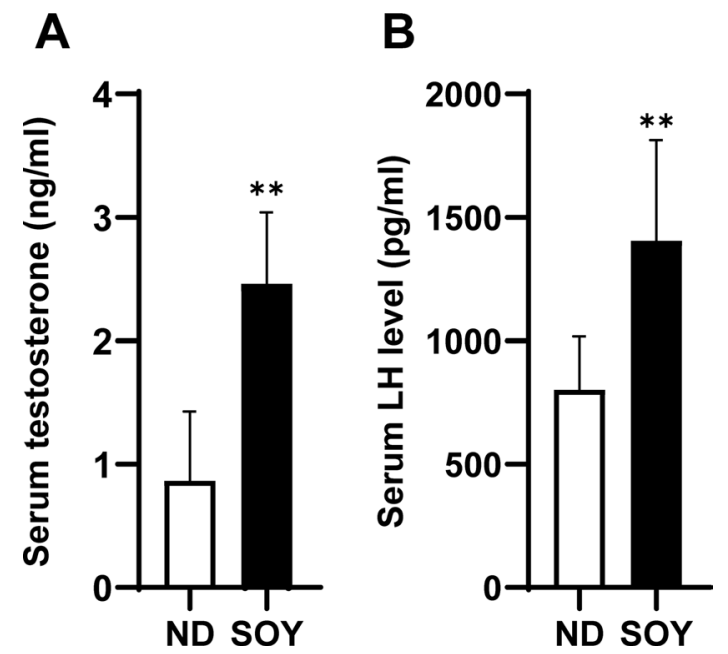

Fig. 2 Increasing intake of soybean oil influenced the serum hormone levels in the mice. A The serum testosterone levels of mice in the ND or SOY group ( $n=5$ for each group). B The serum LH levels of mice in the ND or SOY group ( $n=7$ for each group). Data are expressed as mean $\pm \mathrm{SD}\left({ }^{*} P<0.01\right)$

compared with the ND group, the LHCGR mRNA levels of SOY group had a significant increase $(P<0.05)$. Immunoblotting analysis showed that the protein expression of LHCGR in SOY group increased (Fig. 4B). As expected, immunohistochemistry showed that the expression abundance of LHCGR in testicular Leydig cells in the SOY group was increased in comparison with the quantity of those in the ND group (Fig. 4C). In summary, increasing intake of soybean oil not only increases the level of LH in serum, but also up-regulates the expression of LHCGR in Leydig cells. The changes in hormones and their receptors both affect the production of testosterone.

\section{Discussion}

It is well known that testosterone plays an important role in male development, maintenance of secondary sexual characteristics, sperm production, energy metabolism and many other functions [20, 21]. Many factors, such as unhealthy diet, chronic illnesses etc., all affect the level of testosterone [22].And the decline in serum testosterone has been suggested to be associated with infertility, diminished energy, muscle strength and physical function [23]. Therefore, it is meaningful to explore the causes of testosterone decline and the methods to improve testosterone levels. In recent years, with the changes in the dietary composition, the intake of soybean oil increased. But the effect of increasing intake of soybean oil on testosterone is still not clear. In this study, we demonstrated that increasing intake of soybean oil could improve the serum LH levels and up-regulate the LHCGR. Subsequently,
Table 1 Analysis of the content of fatty acid (FA) in the serum

\begin{tabular}{|c|c|c|}
\hline \multirow[t]{2}{*}{ FA (\%) } & \multicolumn{2}{|l|}{ Group } \\
\hline & ND & SOY \\
\hline \multicolumn{3}{|l|}{ Saturated FA } \\
\hline C14:0 (Myristic acid) & $0.71 \pm 0.07$ & $0.62 \pm 0.02^{*}$ \\
\hline $\mathrm{C} 16: 0(\mathrm{PA})$ & $56.27 \pm 1.08$ & $53.42 \pm 0.98^{* * *}$ \\
\hline C18:0 (Stearic acid) & $26.10 \pm 0.66$ & $26.51 \pm 0.65$ \\
\hline C20:0 (Arachidic acid) & $0.46 \pm 0.03$ & $0.45 \pm 0.02$ \\
\hline C22:0 & $0.15 \pm 0.01$ & $0.14 \pm 0.01$ \\
\hline Total saturated FA & $83.68 \pm 1.55$ & $81.13 \pm 1.60^{*}$ \\
\hline \multicolumn{3}{|l|}{ Monounsaturated FA } \\
\hline C14:1 & $0.31 \pm 0.04$ & $0.26 \pm 0.03^{*}$ \\
\hline C16:1 (Palmitoleic Acid) & $0.65 \pm 0.13$ & $0.51 \pm 0.08$ \\
\hline C18:1 (Oleic acid) & $1.79 \pm 0.22$ & $1.91 \pm 0.38$ \\
\hline C20:1 & $0.29 \pm 0.03$ & $0.26 \pm 0.02$ \\
\hline C22:1 (Erucic acid) & $0.47 \pm 0.02$ & $0.43 \pm 0.04^{*}$ \\
\hline C24:1 & $0.28 \pm 0.02$ & $0.23 \pm 0.02^{* *}$ \\
\hline Total monounsaturated FA & $3.79 \pm 0.22$ & $3.60 \pm 0.44$ \\
\hline \multicolumn{3}{|l|}{$\omega-6$ Polyunsaturated FA } \\
\hline C18:2 $\omega-6(L A)$ & $7.35 \pm 0.98$ & $11.09 \pm 0.99^{* * *}$ \\
\hline C18:3 $\omega-6$ (Y-Linolenic acid) & $0.22 \pm 0.02$ & $0.15 \pm 0.02^{* * *}$ \\
\hline$C 20: 3 \omega-6$ & $0.29 \pm 0.07$ & $0.25 \pm 0.03$ \\
\hline C20:4 $\omega-6(A A)$ & $2.94 \pm 0.48$ & $2.33 \pm 0.43^{*}$ \\
\hline Total $\omega-6$ polyunsaturated FA & $10.81 \pm 1.40$ & $13.82 \pm 1.20^{* *}$ \\
\hline \multicolumn{3}{|l|}{$\omega-3$ Polyunsaturated FA } \\
\hline C18:3 $\omega-3$ (ALA) & $0.25 \pm 0.03$ & $0.42 \pm 0.08^{* * *}$ \\
\hline$C 20: 3 \omega-3$ & $0.32 \pm 0.01$ & $0.29 \pm 0.03^{*}$ \\
\hline$C 20: 5 \omega-3$ (EPA) & $0.28 \pm 0.03$ & $0.17 \pm 0.02^{* * *}$ \\
\hline $\mathrm{C} 22: 6 \omega-3(\mathrm{DHA})$ & $0.86 \pm 0.14$ & $0.57 \pm 0.07^{* * *}$ \\
\hline Total $\omega-3$ polyunsaturated FA & $1.71 \pm 0.17$ & $1.45 \pm 0.11^{*}$ \\
\hline
\end{tabular}

$\mathrm{n}=6$ for each group. Data were presented as mean $\pm \mathrm{SD}\left({ }^{*} P<0.05 ;{ }^{* *} P<0.01\right.$; ${ }^{* * *} P<0.001$ )

PA: Palmitic acid; LA: Linoleic acid; AA: Arachidonic acid; ALA: a-linolenic acid; EPA: Eicosapentaenoic acid; DHA: Docosahexaenoic acid

accompanied by an increase in steroidogenic enzyme expression, the production of testosterone was promoted.

In order to study the effect of increasing intake of soybean oil on testosterone production, we added $20 \%$ soybean salad oil to the diet. There was also no statistical difference in glucose and serum lipids in the SOY group. It is possible that increasing intake of soybean oil did not form an obesity model with hyperlipidemia and hyperglycemia. In order to observe the effect of intake of soybean oil on the fatty acid composition, we analyzed the serum by gas chromatography. The main component of soybean oil is LA, and consistent with that, the serum LA of the mice in SOY group increased significantly. ALA is abundant in soybean oil [24]. Compared with ND group, the serum ALA of SOY group was significantly increased. The major components of soybean oil are PUFAs. Compared with the ND group, increasing intake of soybean 
A

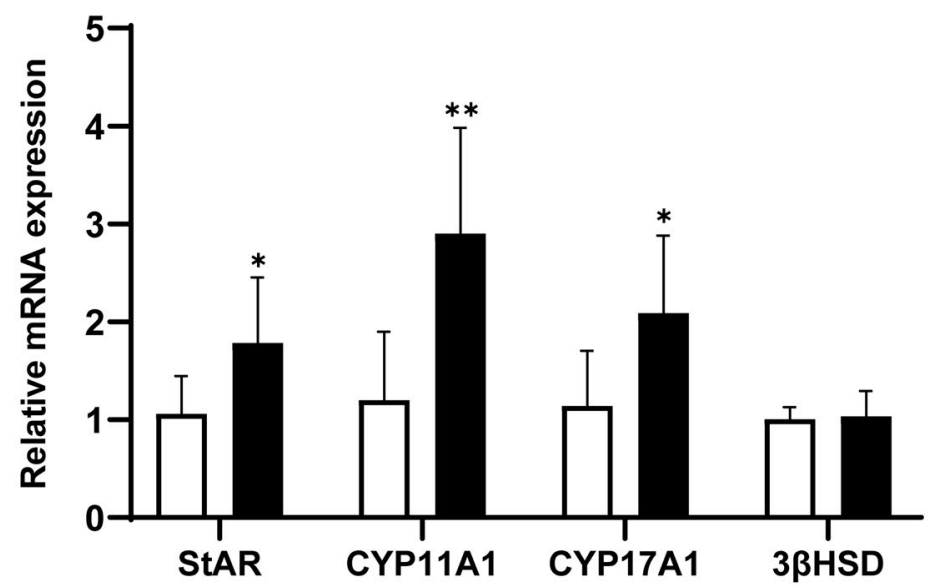

B

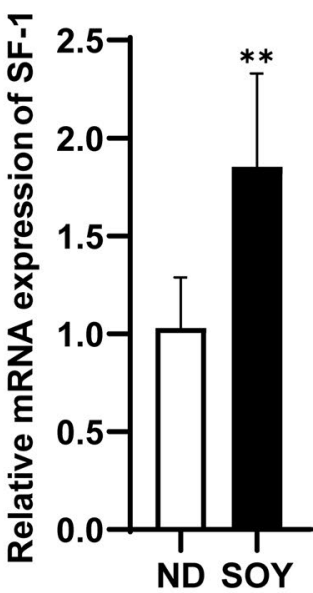

C

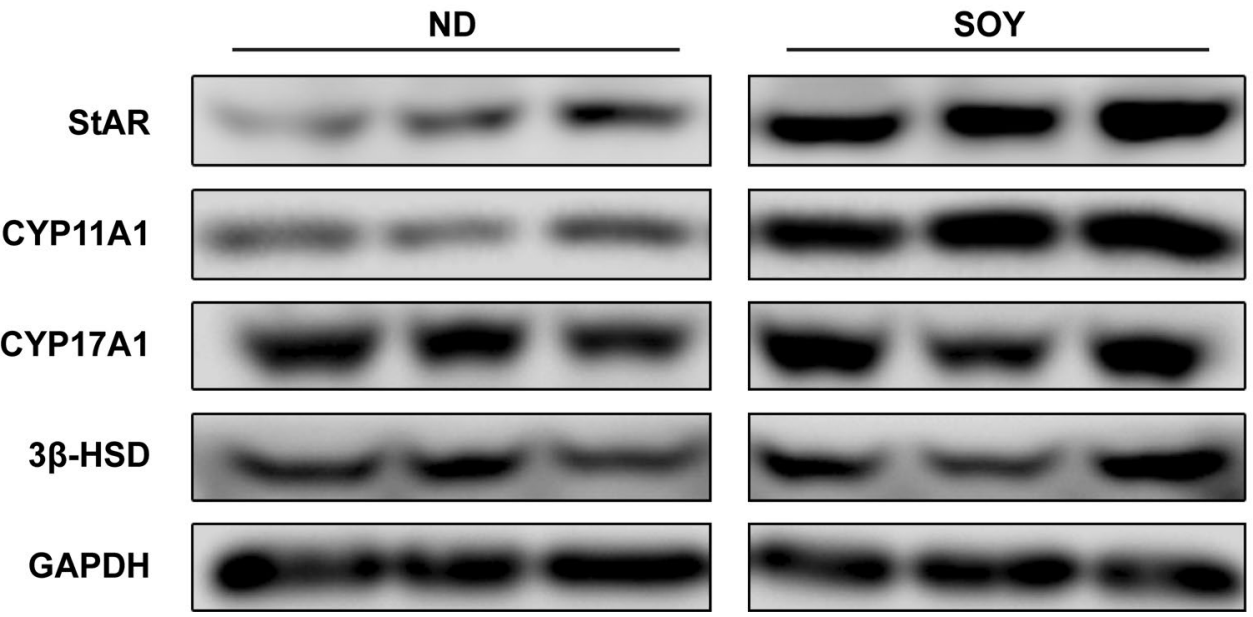

Fig. 3 Increasing intake of soybean oil enhanced steroidogenic enzyme expression in the testis. A RT-PCR analysis of the expression of StAR, CYP11A1, CYP17A1 and 3 $\beta-H S D$ mRNA in testes from mice in the ND or SOY group ( $n=6$ for each group). B RT-PCR analysis of the expression of SF-1 mRNA in testes from mice in the ND or SOY group ( $n=6$ for each group). $\mathbf{C}$ Immunoblot and quantitative analysis of StAR, CYP11A1, CYP17A1 and $3 \beta-H S D$ protein in testes of mice in the ND or SOY group ( $n=3$ for each group). Data are expressed as mean \pm SD $\left({ }^{*} P<0.05, * * P<0.01\right)$

oil reduced the levels of serum saturated fatty acids, especially PA. In agreement with some researches, soybean oil could increase serum LA and ALA levels and decrease saturated fatty acid levels [25-27]. Increasing intake of soybean oil changed the composition of serum fatty acids and that might influence the process of testosterone production.

Dietary LA plays an important role in regulating the balance between inflammation and anti-inflammation and steroid metabolism [28, 29]. A cross-sectional study indicated that a positive association was observed between the intake of PUFAs, particularly of $\omega-6$ PUFAs, and $\mathrm{LH}$ concentrations [30]. It also has been reported that the addition of LA to porcine pituitary cells increased the release of LH [31]. We speculate that soybean oil promotes LH secretion mainly through the increased serum LA levels. Xu A et al. suggested that LA activates the GPR120 / ERK pathway in Leydig cells to promote the production of testosterone directly [32]. In this study, we speculate that in addition to the direct effects of LA on the testis, the testosterone production increased may be the result of the indirect effects of elevated LH levels. We believe that it is at least part of the LH of high levels acts on up-regulated LHCGR that activate the process of testosterone synthesis.

Some findings indicated that feeding of $\omega-3$ PUFAs enriched diet could increase testosterone secretion and improve semen quality [33-36]. ALA, a kind of $\omega-3$ PUFAs, plays an important role in regulating animal reproduction. Qi X et al. suggested ALA could increase 


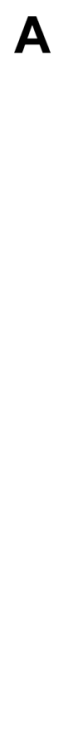

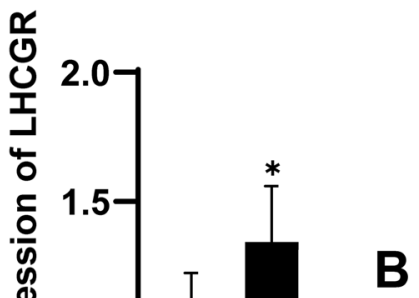

C

ND

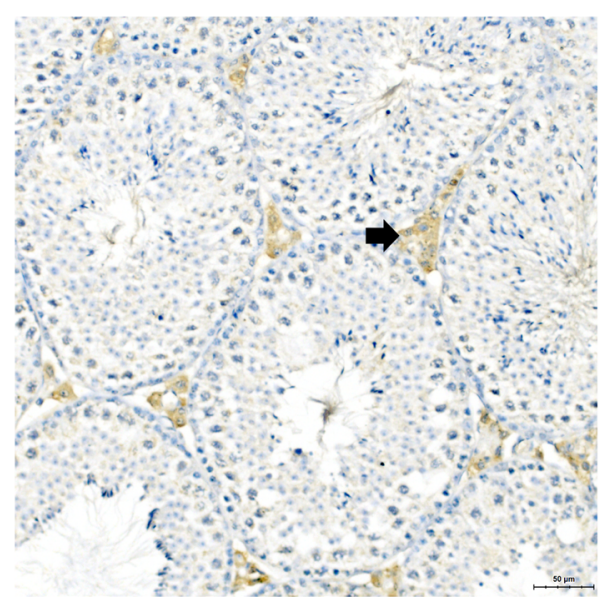

ND

LHCGR

GAPDH
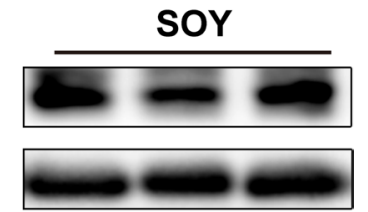

SOY

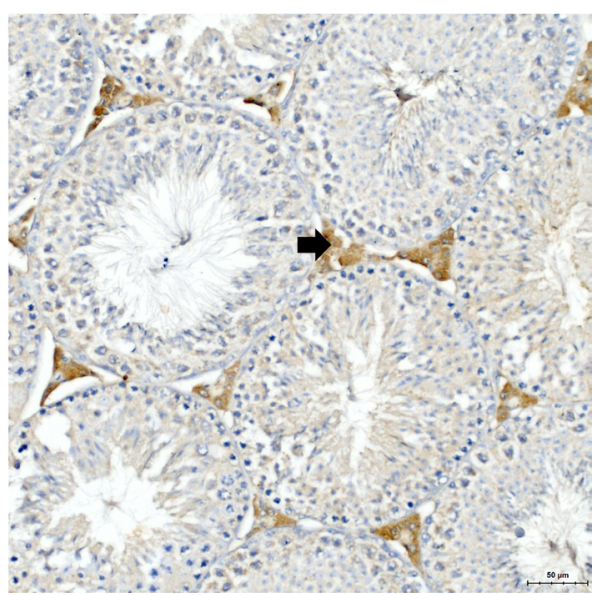

Fig. 4 Increasing intake of soybean oil up-regulated the expression of LHCGR in mice. A RT-PCR analysis of the expression of LHCGR mRNA in testes of mice in the ND or SOY group ( $n=6$ for each group). B Immunoblot and quantitative analysis of LHCGR protein in testes of mice in the ND or SOY group ( $n=3$ for each group). C Testis was immunostained for LHCGR which is expressed in Leydig cells ( $n=3$ for each group). Data are expressed as mean $\pm S D(* P<0.05)$

the testosterone secretion, which may be related to higher StAR and CYP11A1 mRNA expression and SF-1 expression [37]. Soybean oil may promote testosterone synthesis by increasing serum ALA levels.

PA, a kind of saturated fatty acids, could induce apoptosis in testicular Leydig cells and affect testosterone synthesis [38-40]. As this study observed, increasing intake of soybean oil decreased the serum PA levels, which could contribute to the rising of testosterone.

Through the regulating activity of the hypothalamic-pituitary-gonadal axis, the testes exert endocrine functions to produce testosterone [41]. LH acts on Leydig cells to promote the synthesis of testosterone, so we tested the serum LH levels. Compared with the ND group, serum LH levels in mice of the SOY group increased. The up-regulation of LHCGR in the SOY group was more conducive to the function of $\mathrm{LH}$. $\mathrm{LH}$ activated testosterone production, and compared with the ND group, the mRNA levels of SF-1, StAR, CYP11A1, and CYP17A1, the protein expression of StAR and CYP11A1 in the SOY group were all significantly increased. The mRNA levels of CYP17A1 in the SOY group significantly increased compared to ND group, but no significant difference about CYP17A1 at the protein 
levels is discovered. Protein is the working molecules of life activities. In this study, we believe that CYP17A1 may not play a role in increasing testosterone levels. The mRNA levels and protein levels are not always positively correlated in life activities, and the translation of mRNA into protein involves multiple life-regulating processes. CYP17A1 protein levels may be regulated by other processes without change. Consistent with McVey MJ's results, the intake of soybean oil can increase testosterone levels [42]. This study suggested that the increased serum LA and ALA and the decreased serum PA levels affected the above process. The underlying mechanisms need to be further studied.

Testosterone levels affects men's health. Low testosterone levels are associated with an increased fat mass, reduced insulin sensitivity, impaired glucose tolerance, elevation of triglycerides, and cholesterol and low HDLcholesterol [43-47]. All these factors are found in the metabolic syndrome and type 2 diabetes, contributing to cardiovascular risk [21, 48]. Discussing the effects of testosterone on cardiovascular $(\mathrm{CV})$ health is an ongoing debate. The overall evidence suggests that normal physiologic levels of testosterone are beneficial to the male $\mathrm{CV}$ system, and that testosterone deficiency is associated with an unfavorable metabolic profile and increased cardiovascular disease(CVD) events, such as myocardial infarction and mortality [49]. Clinical trials demonstrate that testosterone replacement therapy improves the insulin resistance and glycaemic control, and also reduces body fat mass in particular truncal adiposity, cholesterol, and triglycerides [21]. However, high testosterone levels can also compromise survivorship by increasing risk of prostate cancer, production of oxygen radicals, reduced tissue and organ maintenance, negative energy balance from adipose tissue catabolism, and suppression of immune functions [50]. The relationship between testosterone levels and disease is complicated. In this study, increasing intake of soybean oil raised testosterone levels. This change may reduce the occurrence of clinical disease states of obesity, metabolic syndrome, type 2 diabetes, and CVD, but it also could be associated with an increased risk of other disease. The further studies are required.

In conclusion, we demonstrated that increasing intake soybean oil could raise LH levels, up-regulate LHCGR, improve the steroid synthesis function of Leydig cells, and finally lead to the elevated testosterone levels. Because of the complexity of various fatty acids existing in soybean oil, we speculated that this effect may be caused by a kind of fatty acid alone, and it is more likely to be a comprehensive effect. That proposes a new potential pathway for the treatment of testosterone deficiency. However, further work should be carried out to unveil the underlying molecular mechanisms of the $\mathrm{LH}$ increasing and LHCGR up-regulation. Studies about the subsequent effects of elevated testosterone levels are also needed.

\section{Conclusion}

This study suggests that increasing intake of soybean oil increased the serum LA and ALA levels and decreased serum PA levels, which could activate the LH/LHCGR pathway, improve the function of steroid synthesis in Leydig cells and finally lead to the elevated testosterone levels.

\section{Abbreviations}

SOY: Soybean oil; ND: Normal diet; LA: Linoleic acid; ALA: a-Linolenic acid; PA: Palmitic acid; PUFAs: Polyunsaturated fatty acids; FA: Fatty acid; T: Testosterone; LH: Luteinizing hormone; LHCGR: Luteinizing hormone/chorionic gonadotropin receptor; StAR: Steroidogenic acute regulatory protein; CYP11A1:

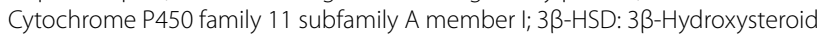
dehydrogenase; CYP17A1: Cytochrome P450 family 17 subfamily A member 1; SF-1: Steroidogenic factor 1; TG: Triglyceride; TC: Total cholesterol; LDL-C: Lowdensity lipoprotein cholesterol; HDL-C: High-density lipoprotein cholesterol; Glu: Glucose; ELISA: Enzyme-linked immunosorbent assay.

\section{Supplementary Information}

The online version contains supplementary material available at https://doi. org/10.1186/s12986-021-00580-1.

Additional file 1: Supplemental Table 1. Ingredients of normal diet.

Additional file 2: Supplemental Table 2. Analysis of the content of fatty acid in the soybeanoil.

Additional file 3: Supplemental Table 3. Analysis of the content of fatty acid in the diets.

\section{Acknowledgements}

Not applicable.

\section{Authors' contributions}

ZH and QG are senior authors, who conceived and designed the experiments; YS, ZT, DL, XQ, LL performed the experiments; DZ, SL and FW analyzed the data; YS wrote the entire paper with suggestions from the senior authors. All authors read and approved the final manuscript.

\section{Funding}

This work was supported by the National Natural Science Foundation of China (81770860, 81641030, and 81471078).

\section{Availability of data and materials}

The datasets used and/or analysed during the current study are available from the corresponding author on reasonable request.

\section{Declarations}

Ethics approval and consent to participate

All animal experiments were approved by the Animal Ethics Committee of Shandong Provincial Hospital and performed according to the Shandong Provincial Hospital Animal Care and Use Committee.

\section{Consent for publication}

Not applicable.

\section{Competing interests}

None. 


\section{Author details}

${ }^{1}$ Department of Endocrinology and Metabolism, Shandong Provincial Hospital, Cheeloo College of Medicine, Shandong University, Jinan 250021, Shandong, China. ${ }^{2}$ Shandong Provincial Key Laboratory of Endocrinology and Lipid Metabolism, Institute of Endocrinology and Metabolism, Shandong Academy of Clinical Medicine, Jinan 250021, Shandong, China. ${ }^{3}$ Department of Endocrinology and Metabolism, Shandong Provincial Hospital Affiliated to Shandong First Medical University, Jinan 250021, Shandong, China. ${ }^{4}$ Department of Clinical Expert, Shandong Provincial Hospital Affiliated to Shandong First Medical University, Jinan 250021, Shandong, China.

Received: 11 January 2021 Accepted: 18 May 2021

Published online: 26 May 2021

\section{References}

1. Nieschlag E, Nieschlag S. ENDOCRINE HISTORY: the history of discovery, synthesis and development of testosterone for clinical use. Eur J Endocrinol. 2019;180(6):R201-12.

2. Chistiakov DA, Myasoedova VA, Melnichenko AA, Grechko AV, Orekhov AN. Role of androgens in cardiovascular pathology. Vasc Health Risk Manag. 2018;14:283-90.

3. Khosla S, Monroe DG. Regulation of bone metabolism by sex steroids. Cold Spring Harb Perspect Med. 2018;8(1):a031211.

4. Lokeshwar SD, Patel P, Fantus RJ, Halpern J, Chang C, Kargi AY, et al. Decline in serum testosterone levels among adolescent and young adult men in the USA. Eur Urol Focus. 2020;S2405-4569(20)30062-6.

5. Tsujimura A. The relationship between testosterone deficiency and men's health. World J Mens Health. 2013;31(2):126-35.

6. Giagulli VA, Guastamacchia E, De Pergola G, lacoviello M, Triggiani V. Testosterone deficiency in male: a risk factor for heart failure. Endocr Metab Immune Disord Drug Targets. 2013;13(1):92-9.

7. Baek Y, Hwang JY, Kim K, Moon HK, Kweon S, Yang J, et al. Dietary intake of fats and fatty acids in the Korean population: Korea National Health and Nutrition Examination Survey, 2013. Nutr Res Pract. 2015;9(6):650-7.

8. Soprani T, Uliana VK, Ribeiro RF Jr, Lisboa S Jr, Maretto GX, da Ferreira AT, et al. Cardiac protein changes in rats after soybean oil treatment: a proteomic study. Lipids Health Dis. 2015;14:26.

9. Hassan HA, Abdel-Wahhab MA. Effect of soybean oil on atherogenic metabolic risks associated with estrogen deficiency in ovariectomized rats: dietary soybean oil modulate atherogenic risks in overiectomized rats. J Physiol Biochem. 2012;68(2):247-53.

10. Rom O, Jeries $H$, Hayek T, Aviram M. Supplementation with linoleic acid-rich soybean oil stimulates macrophage foam cell formation via increased oxidative stress and diacylglycerol acyltransferase1-mediated triglyceride biosynthesis. BioFactors. 2017;43(1):100-16.

11. Villamor E, Marin C, Mora-Plazas M, Casale M, Vargas LN, Baylin A. Cooking with soyabean oil increases whole-blood alpha-linolenic acid in school-aged children: results from a randomized trial. Public Health Nutr. 2015;18(18):3420-8

12. Flannagan KS, Ramirez-Zea M, Roman AV, Das AK, Villamor E. Sociodemographic, anthropometric, and dietary predictors of polyunsaturated fatty acids in adipose tissue among mesoamerican children and their parents. Food Nutr Bull. 2018;39(4):495-511.

13. Blasbalg TL, Hibbeln JR, Ramsden CE, Majchrzak SF, Rawlings RR. Changes in consumption of omega- 3 and omega- 6 fatty acids in the United States during the 20th century. Am J Clin Nutr. 2011;93(5):950-62.

14. Zirkin BR, Papadopoulos V. Leydig cells: formation, function, and regulation. Biol Reprod. 2018;99(1):101-11.

15. Tugaeva KV, Sluchanko NN. Steroidogenic acute regulatory protein: structure, functioning, and regulation. Biochemistry (Mosc). 2019;84(Suppl 1): $\$ 233-53$

16. Miller WL, Auchus RJ. The molecular biology, biochemistry, and physiology of human steroidogenesis and its disorders. Endocr Rev. 2011;32(1):81-151.

17. Payne AH, Hales DB. Overview of steroidogenic enzymes in the pathway from cholesterol to active steroid hormones. Endocr Rev. 2004;25(6):947-70.
18. Hatano M, Migita T, Ohishi T, Shima Y, Ogawa Y, Morohashi Kl, et al. SF-1 deficiency causes lipid accumulation in Leydig cells via suppression of STAR and CYP11A1. Endocrine. 2016;54(2):484-96.

19. Hong CY, Park JH, Ahn RS, Im SY, Choi HS, Soh J, et al. Molecular mechanism of suppression of testicular steroidogenesis by proinflammatory cytokine tumor necrosis factor alpha. Mol Cell Biol. 2004;24(7):2593-604.

20. Kloner RA, Carson C 3rd, Dobs A, Kopecky S, Mohler ER 3rd. Testosterone and cardiovascular disease. J Am Coll Cardiol. 2016;67(5):545-57.

21. Kelly DM, Jones TH. Testosterone: a metabolic hormone in health and disease. J Endocrinol. 2013;217(3):R25-45.

22. Halpern JA, Brannigan RE. Testosterone deficiency. JAMA. 2019:322(11):1116.

23. Hsu B, Cumming RG, Handelsman DJ. Testosterone, frailty and physical function in older men. Expert Rev Endocrinol Metab. 2018;13(3):159-65.

24. Gramlich L, Ireton-Jones C, Miles JM, Morrison M, Pontes-Arruda A. Essential fatty acid requirements and intravenous lipid emulsions. JPEN J Parenter Enteral Nutr. 2019;43(6):697-707.

25. Altenhofer C, Spornraft M, Kienberger H, Rychlik M, Herrmann J, Meyer $\mathrm{HH}$, et al. Effects of rapeseed and soybean oil dietary supplementation on bovine fat metabolism, fatty acid composition and cholesterol levels in milk. J Dairy Res. 2014;81(1):120-8.

26. Benz JM, Tokach MD, Dritz SS, Nelssen JL, DeRouchey JM, Sulabo RC, et al. Effects of choice white grease and soybean oil on growth performance, carcass characteristics, and carcass fat quality of growing-finishing pigs. J Anim Sci. 2011:89(2):404-13.

27. Aguila MB, Pinheiro AR, Aquino JC, Gomes AP, Mandarim-de-Lacerda CA. Different edible oil beneficial effects (canola oil, fish oil, palm oil, olive oil, and soybean oil) on spontaneously hypertensive rat glomerular enlargement and glomeruli number. Prostaglandins Other Lipid Mediat. 2005;76(1-4):74-85.

28. Choque B, Catheline D, Rioux V, Legrand P. Linoleic acid: between doubts and certainties. Biochimie. 2014;96:14-21.

29. Briscoe CP, Tadayyon M, Andrews JL, Benson WG, Chambers JK, Eilert MM, et al. The orphan G protein-coupled receptor GPR40 is activated by medium and long chain fatty acids. J Biol Chem. 2003:278(13):11303-11.

30. Mínguez-Alarcón L, Chavarro JE, Mendiola J, Roca M, Tanrikut C, Vioque J, et al. Fatty acid intake in relation to reproductive hormones and testicular volume among young healthy men. Asian J Androl. 2017;19(2):184-90.

31. Barb CR, Kraeling RR, Rampacek GB. Glucose and free fatty acid modulation of growth hormone and luteinizing hormone secretion by cultured porcine pituitary cells. J Anim Sci. 1995;73(5):1416-23.

32. Xu A, Li X, Li K, Zhang J, Li Y, Gong D, et al. Linoleic acid promotes testosterone production by activating Leydig cell GPR120/ ERK pathway and restores BPA-impaired testicular toxicity. Steroids. 2020;163:108677.

33. Abbott K, Burrows TL, Acharya S, Thota RN, Garg ML. Dietary supplementation with docosahexaenoic acid rich fish oil increases circulating levels of testosterone in overweight and obese men. Prostaglandins Leukot Essent Fatty Acids. 2020;163:102204.

34. Safari Asl R, Shariatmadari F, Sharafi M, Karimi Torshizi MA, Shahverdi A. Improvements in semen quality, sperm fatty acids, and reproductive performance in aged Ross breeder roosters fed a diet supplemented with a moderate ratio of n-3: n-6 fatty acids. Poult Sci. 2018;97(11):4113-21.

35. Tran LV, Malla BA, Sharma AN, Kumar S, Tyagi N, Tyagi AK. Effect of omega-3 and omega-6 polyunsaturated fatty acid enriched diet on plasma IGF-1 and testosterone concentration, puberty and semen quality in male buffalo. Anim Reprod Sci. 2016;173:63-72.

36. Esmaeili V, Shahverdi AH, Alizadeh AR, Alipour H, Chehrazi M. Saturated, omega- 6 and omega-3 dietary fatty acid effects on the characteristics of fresh, frozen-thawed semen and blood parameters in rams. Andrologia. 2014:46(1):42-9.

37. Qi X, Shang M, Chen C, Chen Y, Hua J, Sheng X, et al. Dietary supplementation with linseed oil improves semen quality, reproductive hormone, gene and protein expression related to testosterone synthesis in aging layer breeder roosters. Theriogenology. 2019;131:9-15.

38. Chen Z, Wen D, Wang F, Wang C, Yang L. Curcumin protects against palmitic acid-induced apoptosis via the inhibition of endoplasmic reticulum stress in testicular Leydig cells. Reprod Biol Endocrinol. 2019;17(1):71.

39. Su X, Lin D, Luo D, Sun M, Wang X, Ye J, et al. Cyclophilin D participates in the inhibitory effect of high-fat diet on the expression of steroidogenic acute regulatory protein. J Cell Mol Med. 2019;23(10):6859-71. 
40. Lu ZH, Mu YM, Wang BA, Li XL, Lu JM, Li JY, et al. Saturated free fatty acids, palmitic acid and stearic acid, induce apoptosis by stimulation of ceramide generation in rat testicular Leydig cell. Biochem Biophys Res Commun. 2003;303(4):1002-7.

41. Salonia A, Rastrelli G, Hackett G, Seminara SB, Huhtaniemi IT, Rey RA, et al. Paediatric and adult-onset male hypogonadism. Nat Rev Dis Primers. 2019:5(1):38.

42. McVey MJ, Cooke GM, Curran IH, Chan HM, Kubow S, Lok E, et al. Effects of dietary fats and proteins on rat testicular steroidogenic enzymes and serum testosterone levels. Food Chem Toxicol. 2008;46(1):259-69.

43. Brand JS, Rovers MM, Yeap BB, Schneider HJ, Tuomainen TP, Haring R, et al. Testosterone, sex hormone-binding globulin and the metabolic syndrome in men: an individual participant data meta-analysis of observational studies. PLoS ONE. 2014;9(7):e100409.

44. Brand JS, van der Tweel I, Grobbee DE, Emmelot-Vonk MH, van der Schouw YT. Testosterone, sex hormone-binding globulin and the metabolic syndrome: a systematic review and meta-analysis of observational studies. Int J Epidemiol. 2011;40(1):189-207.

45. Corona G, Monami M, Rastrelli G, Aversa A, Sforza A, Lenzi A, et al. Type 2 diabetes mellitus and testosterone: a meta-analysis study. Int J Androl. 2011;34(6 Pt 1):528-40.
46. Corona G, Monami M, Rastrelli G, Aversa A, Tishova Y, Saad F, et al. Testosterone and metabolic syndrome: a meta-analysis study. J Sex Med. 2011;8(1):272-83.

47. Corona G, Rastrelli G, Maggi M. Diagnosis and treatment of late-onset hypogonadism: systematic review and meta-analysis of TRT outcomes. Best Pract Res Clin Endocrinol Metab. 2013;27(4):557-79.

48. Zarotsky V, Huang MY, Carman W, Morgentaler A, Singhal PK, Coffin D, et al. Systematic literature review of the risk factors, comorbidities, and consequences of hypogonadism in men. Andrology. 2014:2(6):819-34.

49. Elagizi A, Kohler TS, Lavie CJ. Testosterone and cardiovascular health. Mayo Clin Proc. 2018;93(1):83-100.

50. Muehlenbein MP. Adaptive variation in testosterone levels in response to immune activation: empirical and theoretical perspectives. Soc Biol. 2006;53(1-2):13-23.

\section{Publisher's Note}

Springer Nature remains neutral with regard to jurisdictional claims in published maps and institutional affiliations.
Ready to submit your research? Choose BMC and benefit from:

- fast, convenient online submission

- thorough peer review by experienced researchers in your field

- rapid publication on acceptance

- support for research data, including large and complex data types

- gold Open Access which fosters wider collaboration and increased citations

- maximum visibility for your research: over $100 \mathrm{M}$ website views per year

At BMC, research is always in progress.

Learn more biomedcentral.com/submissions 